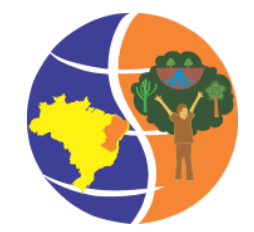

II Simpósio Brasileiro de Recursos Naturais do Semiárido - SBRNS

"Convivência com o Semiárido: Certezas e Incertezas"

Quixadá - Ceará, Brasil

27 a 29 de maio de 2015

ISSN: 2359-2028

\title{
DIFERENTES FORMAS DE ADUBAÇÃO DO GERGELIM EM SOLOS DO VALE DO CANINDÉ, PIAUÍ
}

\author{
Vinicius Evangelista Alves Oliveira ${ }^{1}$, Érica Samara Araújo Barbosa de Almeida ${ }^{2}$, José \\ Rodrigues Pereira ${ }^{3}$, Paulo de Tarso Firmino ${ }^{4}$, Magna Maria Macedo ferreira ${ }^{3}$
}

\footnotetext{
${ }^{1}$ Graduando em Agronomia, UFPB, Areia, PB, 839609 6785, vinicius_oliver@hotmail.com.

${ }^{2}$ Engenheira Agrônoma, Mestranda, Engenharia Agrícola, UFCG, Campina Grande, PB.

${ }^{3}$ D.Sc., Pesquisador, Fitotecnia, Embrapa Algodão, Campina Grande, PB.

${ }^{4}$ M.Sc., Pesquisador, Tecnologia de Alimentos, Embrapa Algodão, Campina Grande, PB
}

RESUMO: A adubação do gergelim é um dos assuntos mais discutidos e controvertidos havendo resultados positivos para determinados locais e cultivares, e negativos em outras situações. Objetivando avaliar a altura e o diâmetro do gergelim BRS Seda, foi conduzido, em Casa de Vegetação, Campina Grande, PB, um experimento no delineamento inteiramente casualizado em esquema fatorial $2 \times 4$, com 3 repetições, sendo os fatores: dois tipos de solo (S1- Solo de baixada; S2- Solo de encosta), coletados na Comunidade Melancia, Bela Vista do Piauí, PI, e 4 formas de adubação (A1- Sem adubação, A2- Adubação orgânica com esterco bovino, A3- Adubação orgânica com esterco caprino e, A4- Adubação mineral = 2580-20 kg ha-1). Aos 56 dias após a emergência, foram avaliadas em 4 plantas, a altura e o diâmetro caulinar. Concluiu-se que os fatores estudados influenciaram a altura de plantas e o diâmetro caulinar do gergelim BRS Seda e que o crescimento em altura e em diâmetro do gergelim BRS Seda no Vale do Canindé, PI, foi maior no solo de encosta quando adubado com esterco caprino e, no solo de baixada, adubado com fertilizantes minerais.

PALAVRAS-CHAVE: Sesamum indicum L., altura de planta, diâmetro caulinar

\section{DIFFERENT SESAME FERTILIZATION FORMS IN CANINDÉ VALLEY SOILS OF PIAUÍ STATE, BRAZIL}

\begin{abstract}
Sesame fertilization is one of the most discussed and controversial issues having positive results for certain locations and cultivars, and negative in other situations. To evaluate the plant height and stem diameter of sesame BRS Seda was conducted in a glasshouse, Campina Grande county, Paraíba State, Brazil, an experiment in a completely randomized design in a $2 \times 4$ factorial scheme with 3 replications, being the factors: two types of soil (S1- lowland soil and S2- soil of slope) collected in Melancia community, Bela Vista do Piauí county, Piauí State, and four fertilization treatments (A1 control, A2- bovine manure; A3- goat manure and A4-25-80-20 mineral fertilization), totaling eight treatments and 24 experimental units. At 56 days after emergence were measured in 4 plants, the plant height and stem diameter. It was concluded that the studied factors influenced plant height and stem diameter of sesame BRS Seda and that the sesame growth in height and diameter in the Canindé Valley, Piauí State, Brazil, was higher in the slope soil when fertilized with goat manure and, in lowland soil, fertilized with mineral fertilizers.
\end{abstract}

KEYWORDS: Sesamum indicum L., plant height, stem diameter 


\section{INTRODUÇÃO}

O gergelim (Sesamum indicum L.) apresenta ampla adaptabilidade às condições edafoclimáticas de clima tropical quente e tolerância a déficit hídrico (BELTRÃO et al., 2010).

Na cultura do gergelim, a adubação é um dos assuntos mais estudados, apresentando respostas diferentes quando se avaliam locais e épocas de cultivo, ou mesmo cultivares (ÁVILA; GRATEROL, 2005). O nitrogênio (N) é o nutriente mais exigido pelo gergelim, influenciando a taxa de expansão e a divisão celular, estimulando o crescimento, atrasando a senescência, mudando a morfologia das plantas e aumentando o conteúdo de clorofila (ARRIEL et. al., 2006). O fósforo (P) é um nutriente essencial bastante requerido pelas plantas, pois é importante em todos os processos metabólicos que envolve gastos de energia como a absorção de nutrientes e a formação dos diferentes órgãos da planta (FRANDOLOSO, 2006). O potássio é considerado essencial para o crescimento, desenvolvimento e qualidade de frutos dos vegetais (PRADO, 2008).

A utilização de adubos orgânicos de origem animal é considerada uma prática útil e econômica para os produtores, favorece a fertilidade e a conservação do solo e proporciona acúmulo de nitrogênio orgânico no solo, aumentando seu potencial de mineralização e de disponibilidade para as plantas (PIRES et al., 2008). Dentre a diversidade de adubos orgânicos existentes o esterco bovino, destaca em diversos aspectos, possui vasta disponibilidade, entre as percentagens de 30 a 58\% de matéria orgânica (PRIMAVESI, 2002). Assim, o presente trabalho teve como objetivo avaliar a altura de plantas e o diâmetro caulinar do gergelim BRS Seda em diferentes formas de adubação em dois tipos de solos do vale do Canindé, PI.

\section{MATERIAL E MÉTODOS}

O experimento foi conduzido em casa de vegetação da Embrapa Algodão, em Campina Grande, PB, nas seguintes coordenadas geográficas: latitude de $7^{\circ} 13^{\prime} \mathrm{S}$, longitude de $35^{\circ} 53^{\prime}$ ' $\mathrm{W}$ e altitude de $547 \mathrm{~m}$.

Os solos da região do município de Bela Vista do Piauí são litólicos, álicos e distróficos, de textura média, pouco desenvolvidos, rasos a muito rasos, fase pedregosa. Associados ocorrem solos podzólicos vermelho-amarelos, textura média a argilosa, fase pedregosa e não pedregosa, ocorrendo também areias quartzosas, que compreendem solos arenosos, profundos, drenados, desprovidos de minerais primários, de baixa fertilidade (CPRM, 2004).

O delineamento experimental foi inteiramente casualisado, em esquema fatorial $2 \times 4$, com 3 repetições, sendo os fatores: dois tipos de solo (S1-Solo de baixada; S2-Solo de encosta), coletados na Comunidade Melancia, município de Bela Vista do Piauí-PI, e quatro 
fontes de adubação (A1- Sem adubação, A2- Adubação orgânica com esterco bovino, A3Adubação orgânica com esterco caprino e A4- Adubação mineral 25-80-20), perfazendo no total oito tratamentos, e de 24 parcelas experimentais. O esterco caprino veio da Comunidade Melancia, município de Bela Vista do Piauí, PI, o esterco bovino foi proveniente da região do Agreste Paraibano.

No solo de Baixada foi feita a correção da acidez com calcário dolomítico na dose de 7 toneladas por hectare, permanecendo incubado por 2 meses para uma calagem efetiva. As parcelas foram constituídas por vasos de $8 \mathrm{~kg}$ de capacidade, preenchidos com solo e adubos na proporção de 3:2, conforme os tratamentos. Os adubos orgânicos foram aplicados na dose de $20 \mathrm{t}$ ha-1. Em cada uma das 2 covas por vaso, espaçadas de $20 \mathrm{~cm}$, foram semeadas 5 sementes, deixando apenas 2 plantas por cova após o desbaste.

Aos 56 dias após a emergência - DAE, foram avaliadas, em 4 plantas, a altura medindose, em centímetros, a distância compreendida da base até o ponteiro do caule principal da planta e o diâmetro caulinar (mm), com auxílio de um paquímetro simples, medido a um centímetro em relação ao nível do solo.

Feita análise de variância, as médias dos fatores foram comparadas pelo teste de Tukey à 5\% de probabilidade pelo software SISVAR (FERREIRA, 2011).

\section{RESULTADOS E DISCUSSÃO}

Os resultados das variáveis foram submetidos a análise de variância, observando para o fator Solo (S) que nenhuma das variáveis analisadas apresentaram valores significativos, enquanto que para o fator Adubação (A) apenas a altura de planta (AP) foi significativa. A interação entre os fatores (S X A), por sua vez, foi estatisticamente significativa nas duas variáveis analisadas (Tabela 1 ).

Possivelmente no solo de Baixada, a lixiviação dos nutrientes foi preponderante promovendo a perca de nutrientes adicionados ao solo pelas diferentes formas de adubação fazendo com que comportassem como se não houvesse feito adubação (igual ao tratamento testemunha) (Tabela 2), no que corrobora van Raij (1991) que afirma, em solos com capacidade de armazenamento de água limitada, bem drenados, própria de solos de textura arenosa, o solo de Baixada do presente experimento, a lixiviação de nutrientes, por meio da água que percola através do perfil do solo, ocorre mais rapidamente. 
Tabela 1. Quadrados médios do resíduo da altura (AP) e do diâmetro caulinar (DC) de plantas do gergelim BRS Seda em diferentes tipos solos e de adubação. Campina Grande, PB. 2014

\begin{tabular}{lccc}
\hline Fonte de variação & GL & $\begin{array}{c}\text { AP } \\
(\mathrm{cm})\end{array}$ & $\begin{array}{c}\text { DC } \\
(\mathrm{mm})\end{array}$ \\
\hline SOLO (S) & 1 & $48,16 \mathrm{~ns}$ & $0,98 \mathrm{~ns}$ \\
ADUBAÇÃO (A) & 3 & $635,82^{*}$ & $6,73 \mathrm{~ns}$ \\
S X A & 3 & $1576,35^{* *}$ & $22,80^{* *}$ \\
RESÍDUO & 16 & 185,35 & 4,68 \\
\hline CV (\%) & - & 60,01 & 60,01 \\
MÉDIA & - & 22,68 & 3,60 \\
\hline
\end{tabular}

* Significativo $(\mathrm{p}<0,05),{ }^{* *}$ significativo $(\mathrm{p}<0,01)$, ns não significativo $(\mathrm{p}>0,05)$

Tabela 2. Desdobramento da interação na variável altura de plantas do gergelim BRS Seda em diferentes tipos solos e de adubação. Campina Grande, PB. 2014

\begin{tabular}{|c|c|c|c|c|c|}
\hline \multirow[t]{2}{*}{ SOLO } & \multicolumn{4}{|c|}{ ADUBAÇÃO } & \multirow{2}{*}{ DMS } \\
\hline & Testemunha & $\begin{array}{l}\text { Esterco } \\
\text { Bovino }\end{array}$ & $\begin{array}{c}\text { Esterco } \\
\text { Caprino }\end{array}$ & Mineral & \\
\hline Baixada & $16,25 \mathrm{aA}$ & $13,91 \mathrm{aA}$ & $13,80 \mathrm{bA}$ & $41,09 \mathrm{aA}$ & 31,81 \\
\hline Encosta & $8,93 \mathrm{aB}$ & $20,62 \mathrm{aB}$ & $58,60 \mathrm{aA}$ & $8,24 \mathrm{bB}$ & 31,81 \\
\hline DMS & 23,56 & 23,56 & 23,56 & 23,56 & - \\
\hline
\end{tabular}

Médias seguidas das mesmas letras minúsculas, nas colunas, e maiúsculas, nas linhas, não diferem entre si pelo teste de Tukey a $5 \%$ de probabilidade.

No solo de Encosta, de textura argilosa, a adubação orgânica com esterco caprino se destacou das demais formas de adubação estudadas (Tabela 2), provavelmente porque, segundo afirma Malavolta et al. (2002), este tipo de esterco fermenta rapidamente podendo ser aproveitado na agricultura após um menor período de decomposição que os demais, superando inclusive a adubação mineral (Tabela 2) possivelmente, por proporcionar melhor conservação da umidade e consequente melhor reação no solo que aquela, conforme também afirma van Raij (1991).

No solo de Encosta, de textura argilosa, a adubação orgânica com esterco caprino destacou das demais formas de adubação estudadas (Tabela 3), provavelmente porque demanda menor período de decomposição que os demais, superando inclusive a adubação mineral possivelmente, por proporcionar melhor conservação da umidade e consequente melhor reação no solo, conforme comentários anteriores feitos por van Raij (1991), Malavolta et al. (2002) e Souto et al. (2005).

Quanto ao fato de, comparada às demais adubações e isoladamente, a adubação mineral promover maior crescimento em diâmetro no solo de baixada (Tabela 3), possivelmente a correção do solo pode ter favorecido um melhor equilíbrio nutricional e solubilidade na 
solução do solo promovendo melhor resposta da adubação mineral nesse tipo de solo, pois segundo Malavolta (1980) a calagem tem como consequências diminuir as concentrações tóxicas de $\mathrm{Al}$ e $\mathrm{Mn}$, melhorar as condições para a vida de microrganismos decompositores da matéria orgânica liberando $\mathrm{N}, \mathrm{P}, \mathrm{S}$ e $\mathrm{B}$, aumentar a disponibilidade de $\mathrm{P}$ e $\mathrm{MO}$, fornece $\mathrm{Ca}$ e $\mathrm{Mg}$, melhorar as condições de vida para os organismos responsáveis pela nitrificação e pela fixação simbiótica do $\mathrm{N}_{2}$ e melhorar as propriedades físicas do solo através da agregação permitindo desenvolvimento das raízes, aumentando a aeração e circulação de água.

Tabela 3. Desdobramento da interação na variável diâmetro caulinar de plantas de gergelim BRS Seda em diferentes tipos solos e de adubação. Campina Grande, PB. 2014

\begin{tabular}{cccccc}
\hline SOLO & \multicolumn{2}{c}{ ADUBAÇÃO } & DMS \\
\hline & Testemunha & $\begin{array}{l}\text { Esterco } \\
\text { Bovino }\end{array}$ & $\begin{array}{c}\text { Esterco } \\
\text { Caprino }\end{array}$ & Mineral & \\
\hline Baixada & $2,91 \mathrm{aAB}$ & $2,85 \mathrm{aAB}$ & $2,03 \mathrm{bB}$ & $7,43 \mathrm{aA}$ & 5,05 \\
Encosta & $2,13 \mathrm{aA}$ & $3,01 \mathrm{aA}$ & $6,28 \mathrm{aA}$ & $2,18 \mathrm{bA}$ & 5,05 \\
\hline DMS & 3,74 & 3,74 & 3,74 & 3,74 & - \\
\hline
\end{tabular}

Médias seguidas das mesmas letras minúsculas, nas colunas, e maiúsculas, nas linhas, não diferem entre si pelo teste de Tukey a $5 \%$ de probabilidade.

O esterco caprino propiciou melhor crescimento em diâmetro das plantas em solo de encosta (Tabela 3), provavelmente por este tipo de solo agregar melhor a propriedade física de promoção de porosidade e agregação do solo por esse esterco, pois conforme van Raij (1991), a matéria orgânica atua na estruturação do solo através de polímeros com cargas, que unem as partículas isoladas de argila, formando agregados, visto que partículas finas ou coloidais, tipo da matéria orgânica, têm alta tensão superficial significando isso alta capacidade de retenção de cátions e de água.

Por fim a adubação testemunha e a adubação orgânica com esterco bovino comportaram-se igualmente nos dois tipos de solo (Tabela 3) porque ou não houve adubação, caso da testemunha ou não houve tempo para decomposição dos nutrientes, caso do esterco bovino (Tabela 5), conforme comentado anteriormente por Souto et al. (2005).

\section{CONCLUSÕES}

Os fatores estudados influenciaram a altura de plantas e o diâmetro caulinar do gergelim BRS Seda. O crescimento em altura e em diâmetro do gergelim BRS Seda no Vale do Canindé, PI, foi maior no solo de encosta quando adubado com esterco caprino e, no solo de baixada, adubado com fertilizantes minerais. 


\section{REFERÊNCIAS}

ARRIEL, N. H. C.; FIRMINO, P. T.; BELTRÃO, N. E.de M.; SOARES, J. J.; ARAÚJO, A. E.; SILVA, A. C.; FERREIRA, G. B. A cultura do gergelim. Brasília: Embrapa Informação Tecnológica, 2006. 72p. (Cartilha Plantar, 50).

ÁVILA, J. M.; GRATEROL, Y. E. Planting date, row spacing and fertilizer effects on growth and yield of sesame (Sesamum indicum L.). Bioagro, v.17, n.1, p.35-40, 2005.

BELTRÃO, N. E. de M.; VALE, L. S.; MARQUES, L. F.; CARDOSO, G. D.; MARACAJA, P. B. Época relativa de plantio no consórcio mamona e gergelim. Revista Verde de Agricultura e Desenvolvimento Sustentável, v.5, n.5, p-67-73, 2010.

CPRM - SERVIÇO GEOLÓGICO DO BRASIL. Projeto cadastro de fontes de abastecimento por água subterrânea. Estado do Piauí. Diagnóstico do município de Bela Vista do Piauí-PI. Fortaleza: Secretaria de Desenvolvimento Energético/Secretaria de Minas e Metalurgia/ Ministério de Minas e Energia. 2004, 18p.

FERREIRA, D. F. Sisvar: a computer statistical analysis system. Ciência e Agrotecnologia, v.35, n.6, p.1039-1042, 2011.

FRANDOLOSO, J. F. Eficiência de adubos fosfatados associados a enxofre elementar na cultura do milho. 2006. 63p. Dissertação (Mestrado em Agronomia) Universidade Estadual do Oeste do Paraná, Marechal Cândido Rondon.

MALAVOLTA, E. Elementos de nutrição mineral de plantas. São Paulo: Ceres, 1980. 255p.

MAlavolta, E.; GOMES, F.P.; ALCARDE, J. C. Adubos e Adubações. São Paulo: Nobel, 2002. 200p.

PIRES, A. A.; MONNERAT, H. P.; MARCIANO, C. R.; PINHO, L. G. R.; ZAMPIROLLI, P. D.; ROSA, R. C.; MUNIZ, R. A. Efeito da adubação alternativa do maracujazeiro amarelo nas características químicas e físicas do solo. Revista Brasileira de Ciência do Solo, v.32, n.5, p.1997-2005, 2008.

PRADO, R. M. Nutrição de plantas. São Paulo: UNESP, 2008, 407p.

PRIMAVESI, A. Manejo Ecológico do solo: a agricultura em regiões tropicais. São Paulo: Nobel, 2002.

SOUTO, P. C.; SOUTO, J. S.; SANTOS, R. V.; ARAÚJO, G. T.; SOUTO, L. S. Decomposição de estercos dispostos em diferentes profundidades em área degradada no Semiárido da Paraíba. Revista Brasileira de Ciências do Solo, v.29, p.125-130, 2005.

VAN RAIJ, B. Fertilidade do solo e adubação. Piracicaba: Ceres/Potafos, cap.1, 1991. $343 p$. 